\title{
A Performance of Ingenuity Research using Bibliometric Method
}

\author{
Azharudin Ali, Aidi Ahmi,Siti Zabedah Saidin
}

\begin{abstract}
The age of fast modifications across the digital and new technology-driven economy, artificial intelligence, and fast cycles of product life have made engineering important for worldwide economic and social development. Further, ingenuity is also crucialinconfronting the uncertainties and challenges brought byIndustrial Revolution 4.0 (IR4.0) and dynamic businessenvironment.Hence, this studyaims to analyze and look atthetitleof papersand articles on the ingenuity studies derived from Scopus database. By and large, ingenuity is defined as "the quality of inventive, original andnovelty", This means an intrinsic or inborn skill for practical ideas, intelligence, ingenuity, creativity, and the ability to innovate, solve issues, and generate fresh stuff and ideas. In this study, the coverage we reviewed on ingenuity titles includes multidisciplines and regions from the entire perspective of ingenuity studies, not limited to the ingenuity of technology, science, production and engineering.Thus, it providesa profile and insights into the behavioursand attributesof the ingenuity study to discovera title of publications and researchevidenceor expectednessthat possibly will occur in papers.Data are collectedemployinga bibliometric approach to analyze the titles of papers, research and publications that have been listed and indexed by Scopus(exclude the publicationyear 2018). Therefore, all articles fromvarious type of documents and sourcesthat have ingenuity keyword in its title including author keywords and abstracts in the Scopus databasehas been obtained and analyzed.The result showsa total of 465 papers are obtainablefor further analysis after carrying out the cleanup process. Furthermore, it indicatesabout 75 percent or 346 out of 465 articles came from journals source type that has the ingenuity keywords in its.The outcomes of this bibliometric analysisarefound to be usefulfor researchersin providing valuable insight and understanding about the prospect and outlook of the global research on ingenuity as well as in finding future research direction.
\end{abstract}

Keyword: Ingenuity, Bibliometric Analysis, Scopus Database

\section{INTRODUCTION}

Ingenuityis animperativedriver for boostingfuture growth, productivity andsustainable economic prosperity. Where a dynamic ingenuity ecosystem entailsinnovative, novel and creative qualitythat is crucial to move anyonefrom being an inventor follower (amarketfollower) to becomea leader.One of the primary challenges in thinking about ingenuity is the plethora of definitions and meanings of the term ingenuity.

Revised Manuscript Received on June 22, 2019.

Azharudin Ali, TunkuPuteriIntanSafinaz School of Accountancy, Universiti Utara Malaysia 06010 UUM Sintok, Kedah, Malaysia

Aidi Ahmi, TunkuPuteriIntanSafinaz School of Accountancy, Universiti Utara Malaysia 06010 UUM Sintok, Kedah, Malaysia

Siti Zabedah Saidin, TunkuPuteriIntanSafinaz School of Accountancy, Universiti Utara Malaysia 06010 UUM Sintok, Kedah, Malaysia
Ingenuity is one of those terms spotteda lot in the articles, daily newspaper andmass mediawithmany different meanings and interpretations. The word "ingenuity" stem from the Latin word"ingenuitas" (means ingenuousness), which came from the word ingenuus (inborn). However, when this Latin wordwas adopted into English, it combines the two words: ingenious (skillful, intelligent) and ingenuous (high-minded). Thus, ingenuity may portray different meanings, both within the literature and in normal usage, in line with the context of its use in diverse professions and disciplines. The pivotal issue about ingenuity is whether the term iswidely use across diverse fields and disciplinesor only limited to certain fields. In general, the mass media and public at large have a tendency for lavish attention on the ingenuity of information systemand high-techfields, but marginalizes the ingenuity found in more traditional fields. For example, many people perceivedingenuity as a new creation, innovation and creativity made by the computer, engineering and information technology experts, tosolve complex problems in specific area. The Oxford English Dictionary describes ingenuity as "the quality of being smart, original, and inventive," implying an intrinsic or inborn skill for having practical ideas, being smart, ingenious, creative, and capable of innovating, overcoming issues, and producing fresh stuff and ideas. While, according to McGregor[1]ingenuity is "the quality of being imaginative, creative, and capable of using these characteristics to address organisational issues and improve stuff." The Merriam-Webster Dictionary also describes ingenuity as "skill or cleverness that allows someone to solve problems or invent things." Such definitions therefore imply that ingenuity is not simply privileged and restricted to the areas of technology, science, computing, engineering, data and communication.

Alternatively, in relation to the significance of language ingenuity, Homer-Dixon[2] describes ingenuity as "concepts used to address practical, social and technical issues." This definition suggests that ingenuity does not necessarily imply a fresh or innovative concept, but all concepts that are helpful in solving practical issues can be inferred. Despite the fact that innovation needs a fresh development, invention and novelty, practical ideas can include novel and worldly thoughts and still be ingeniousAccordingly, it implies that the word of ingenuity is quite wide in its applicability, not just creative ideas[3, 4]. In a broader context, ingenuity involves human thought, action, work, morals, behaviors, ethics, operations, invention, development, transformation, and the management of items and interactions.

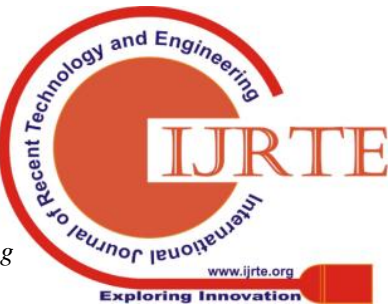


Hence human ingenuity has resulted to a variety of innovations in science, technology, social, economic, financial, transportation, education, health care, data and communication, industrialization, agriculture, industry and politics. Overall, the creativity and ability of humans to produce, innovate, transform, and enhance their quality of life, business, and multiple interactions between people, institutions, organisations, societies, and countries has been significantly impacted by ingenuity.

On the other side, in his studies and writing on the notion of ingenuity, Homer-Dixon[2 ] claims that ingenuity is a comparatively new field of studies, but that it can be regarded as one of the significant areas of research and development of fresh information and human advancement, making ingenuity studies an significant issue and superior study choice. In the original stage, a big quantity of ingenuous studies concentrated on the role of ingenuity, innovation, and thoughts as an inherent productive force that represents a important contribution to financial growth and development[2 ] embodied in people, organizations, and techniques. As the trend has progressed over the past five years, however, it has been to explore other forms of ingenuity, which is ' organizational ingenuity ' consisting of: large organizations[5 ], high-tech entrepreneurial start-ups[6 ], R\&D teams[7 ], engineering consulting firms[8 ], the solar energy industry[9], flash smelting in the copper industry[10 ], haute cuisine[11 ], and microfinance[12 ]. These studies generally show how organizations and their members can produce ingenious solutions to problems so that improvements can be made to ensure sustained competitive advantage, better performance, and the achievement of organizational goals and long-term operational success[13 ]. This study seeks to explore ingenuity research and trend across the globe across all disciplines and areas as an attempt to profile and understand the trend of ingenuity studies.

With the apparently simple premise of universal outlook of ingenuity concept, ingenuity research is evolving to discover all fields and disciplines of studies. It is redrawing the map of ingenuity research. As barriers to narrow scope that contained only certain fields are removed, ingenuity research disciplines and fields are being redefined. Value criteria are shifting, and new studies structures are emerging around humans, technologies, systems, organizations, sciences, socials and economic dimension, which are widely use across diverse fields and disciplines, both in the user's realm and in the innovator's domain. Ingenuity's concept of what it isabout, and what it can be embraced, are evolving and expending in more disciplines and fields.For example, Lampel et al.[13 ] extended the general use of terms of ingenuity beyond the fields of technology, science, humaningenuity, and engineering,[13 ] denotes the concept of ingenuity centered on organizational ingenuity.In this context, ingenuity is defined by Lampel et al.[13 ] as: "the capacity to generate innovative alternatives within structural limitations using restricted funds and imaginative problemsolving." Accordingly, Ungerer et al.[14 ] describes organisational ingenuity as "having an appropriate flow of the correct types of creative thoughts and understanding the factors that regulate that flow." In addition, Ungerer et al.[14] emphasize that organizational ingenuity occurs when both "things" (new products and services) and "social" innovations (new interrelationships between people, organizations, institutions and communities) materialize within the organization. Organizational ingenuity can therefore be used sensibly to enable an organization to improve, survive and become more competitive. This is anticipated to give more bravery and boost study operations that use the word ingenuity.

Considering the above development and condition, there are many issues and interests that attract and encourage researchers to explore and conduct research using the concept of ingenuity across various disciplines, settings and fields[13]. There can be much higher use and roles with the ingenuity word, with the vibrant and changing disciplines and areas of studies. Innovation, creativity, scare resources, development of technology, as well as operational, organizational, economic and social developments are complicated problems. All of these are essential for the analysis of current and new ingenuity studies across diverse research areas, kinds, forms (centralize vs. decentralize, inner vs. external), relationships and perspectives. The aim of this document is therefore to examine the profile, trend and primary characteristics of ingenuity study.

\section{METHODS}

For the bibliometricians, the assessment of keywords and articles and records titles has continually been an appealing and notable area of studies. This study is thus carried out by exploiting the bibliometric method that is widely used in various science and engineering fields for scientific development and research trends[15,16]. Typically, this method evaluates the study trend based on citation analysis[17] and publishing outputs based on nations, years, document types and areas of research[18]. However, the citations analysis and publishing outputs can not fully demonstrate the direction and recent trend of the study sector based on nations and study journals. Instead, more information source should be regarded, including title, author keywords, keywords plus, and abstracts, to study the study trend. On the other side, Bayer and Folger[19 ] have disclosed that database sources such as the Social Science Citation Index (SSCI) and the Institute for Scientific Information (ISI) Web of Science are the most common and widely used as a selection for a comprehensive evaluation of scientific completion in all fields of research. The keyword search in the SSCI and the ISI database provided an additional overview of advance texts and search terminology extracted in their bibliographies and footnotes from article titles quoted by authors[20 ]. This research used both the standard technique (including the field of study and nation assessment) and the innovative process (source title, writer keyword, and keyword plus evaluation) to investigate, discover and map full ingenuity study information from the Scopus database (but exclude information from the year 2018).

This study used the Scopus database to collect all studies containing the term "ingenuity" in the paper's title. and Engin 0 IJTRTE 范 幽

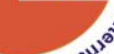
Sciences Publication 
A query was performed (TITLE (ingenuity) AND (EXCLUDE (PUBYEAR,2018))) resulting in 465 results. This study used a bibliometric method to analyze the data base output to define the research and publishing trend on the study of ingenuity. This method will be used to acquire the information required as it provides the scientist with an opportunity to uncover prevailing trends in the identification of ingenuity studies.

\section{RESULTS AND DISCUSSION}

The following elements have accessed and evaluated all the documents acquired: document type and source type, year of publishing, nation, language, topic region, and keyword. The further assessment will also be performed on the paper's title.

\section{Type of Documents and Source}

This document evaluated the allocation of the Scopus recognized document type as well as the document source. Overall, 12 kinds of document generated from ingenuity studies were discovered in this study. Journal paper is the most document form generated, representing over $50 \%$ of document kinds out of 465 journals in total. The results show that journal article (253) was the most frequently used of document type covering 54.41 percent of the complete publishing, followed by conference paper (43;9.25 percent), review paper $(38 ; 8.17$ percent), note $(36 ; 7.74$ percent), book chapter $(27 ; 5.81$ percent), letter $(25,5.38$ percent), and editorial paper $(23,4.95)$. The other less influence document form included brief study (12), conference review (3), press article (3), book (1) and erratum (1). Table 1 shows the overview of this finding.

Table. 1Document Type

\begin{tabular}{lll}
\hline Document Type & Frequency & Percent $(\%)$ \\
\hline Article & 253 & 54.41 \\
Conference Paper & 43 & 9.25 \\
Review & 38 & 8.17 \\
Note & 36 & 7.74 \\
Book Chapter & 27 & 5.81 \\
Letter & 25 & 5.38
\end{tabular}

\begin{tabular}{lll} 
Editorial & 23 & 4.95 \\
Short Survey & 12 & 2.58 \\
Conference Review & 3 & 0.65 \\
Article in Press & 3 & 0.65 \\
Book & 1 & 0.22 \\
Erratum & 1 & 0.22 \\
\hline Total & 465 & 100.00 \\
\hline
\end{tabular}

This study also found five (5) source types of article written from ingenuity research. Most of the articles come from the journals source represented almost two-third (346, $74.41 \%$ ) of the total publicationsfollowed by trade publication $(53 ; 11.40 \%)$, conference proceedings $(34$; $7.31 \%)$, book $(27 ; 5.81 \%)$, and book series $(5 ; 1.08 \%)$. The summary of this finding is shown in Table 2.The extensive papers published as journal articles implied that ingenuity researchers are more interested to contribute their research findings through a periodical publication relating to a certain academic discipline,andact as forum for discussion of research.

Table. 2 Source Type

\begin{tabular}{lll}
\hline Source Type & Frequency & Percent (\%) \\
\hline Journals & 346 & 74.41 \\
Trade Publications & 53 & 11.40 \\
Conference Proceedings & 34 & 7.31 \\
Books & 27 & 5.81 \\
Book Series & 5 & 1.08 \\
\hline Total & 465 & 100.00 \\
\hline
\end{tabular}

\section{Year of Publication}

The distribution of the total number of articles that has been published by year is shown in Table 3. The greater number of publications associated to ingenuity was in 2014 , representing $7.86 \%$ of the total publication on ingenuity since 1854. The result shows the number of publications begin to increase in 2001 and drop in 2004. However, in 2005it increases with a fluctuation trend of publication until 2017. This behavior may indicate that ingenuity is still an unfamiliar and a new concept to some researchers and a relatively new field of study.
Table. 3 Year of Publications

\begin{tabular}{llc}
\hline Year & Frequency & Percent $(\%)$ \\
\hline 2017 & 18 & 3.82 \\
2016 & 19 & 4.03 \\
2015 & 20 & 4.25 \\
2014 & 37 & 7.86 \\
2013 & 17 & 3.61 \\
2012 & 28 & 5.94 \\
2011 & 30 & 6.37 \\
2010 & 17 & 3.61 \\
2009 & 19 & 4.03 \\
2008 & 19 & 4.03 \\
2007 & 22 & 4.67 \\
2006 & 20 & 4.25 \\
2005 & 14 & 2.97 \\
\hline
\end{tabular}

\begin{tabular}{clc}
\hline Year & Frequency & Percent $(\%)$ \\
\hline 1994 & 4 & 0.85 \\
1993 & 5 & 1.06 \\
1991 & 5 & 1.06 \\
1990 & 5 & 1.06 \\
1989 & 4 & 0.85 \\
1988 & 5 & 1.06 \\
1986 & 7 & 1.49 \\
1985 & 3 & 0.64 \\
1984 & 3 & 0.64 \\
1983 & 4 & 0.85 \\
1982 & 2 & 0.42 \\
1981 & 1 & 0.21 \\
1980 & 1 & 0.21 \\
\hline
\end{tabular}

\begin{tabular}{|c|c|c|}
\hline Year & Frequency & Percent (\%) \\
\hline 1967 & 2 & 0.42 \\
\hline 1966 & 2 & 0.42 \\
\hline 1965 & 2 & 0.42 \\
\hline 1957 & 1 & 0.21 \\
\hline 1956 & 1 & 0.21 \\
\hline 1952 & 5 & 1.06 \\
\hline 1951 & 1 & 0.21 \\
\hline 1950 & 1 & 0.21 \\
\hline 1938 & 1 & 0.21 \\
\hline 1931 & 1 & 0.21 \\
\hline 1929 & 1 & 0.21 \\
\hline 1925 & 1 & 0.21 \\
\hline 1906 & 1 & 0.21 \\
\hline
\end{tabular}




\begin{tabular}{lll}
\hline 2004 & 5 & 1.06 \\
2003 & 15 & 3.18 \\
2002 & 10 & 2.12 \\
2001 & 9 & 1.91 \\
2000 & 4 & 0.85 \\
1999 & 6 & 1.27 \\
1998 & 5 & 1.06 \\
1997 & 3 & 0.64 \\
1996 & 3 & 0.64 \\
1995 & 6 & 1.27 \\
\hline
\end{tabular}

\begin{tabular}{lll}
\hline 1979 & 9 & 1.91 \\
1978 & 1 & 0.21 \\
1977 & 4 & 0.85 \\
1976 & 3 & 0.64 \\
1974 & 1 & 0.21 \\
1973 & 4 & 0.85 \\
1971 & 4 & 0.85 \\
1970 & 1 & 0.21 \\
1969 & 2 & 0.42 \\
1968 & 3 & 0.64 \\
\hline
\end{tabular}

\begin{tabular}{lll}
\hline 1895 & 1 & 0.21 \\
1889 & 1 & 0.21 \\
1886 & 8 & 1.70 \\
1874 & 1 & 0.21 \\
1873 & 1 & 0.21 \\
1869 & 1 & 0.21 \\
1866 & 1 & 0.21 \\
1860 & 2 & 0.42 \\
1854 & 2 & 0.42 \\
\hline
\end{tabular}

\section{Country}

This paper also analyzed the dissemination of the paper based on country that was initiated based on the origin of the author. This study found most of the papers are originated from United States (111) followed by United Kingdom (42), Canada (26) and Israel (21). The summary of this finding is shown in Table 4.

Table. 4 Country

\begin{tabular}{ll}
\hline Country & Total \\
\hline United States & 111 \\
United & 42 \\
Kingdom & \\
Canada & 26 \\
Israel & 21 \\
China & 11 \\
Germany & 11 \\
Japan & 8 \\
Australia & 7 \\
India & 7 \\
Switzerland & 7 \\
Spain & 6 \\
Brazil & 4 \\
Italy & 3 \\
Netherlands & 3 \\
Poland & 3 \\
South Africa & 3 \\
Sweden & 3 \\
Finland & 2 \\
Ireland & 2 \\
\hline
\end{tabular}

\begin{tabular}{ll}
\hline Country & Total \\
\hline New Zealand & 2 \\
Belgium & 1 \\
& \\
Denmark & 1 \\
Estonia & 1 \\
France & 1 \\
Ghana & 1 \\
Hong Kong & 1 \\
Hungary & 1 \\
Kenya & 1 \\
Lithuania & 1 \\
Nigeria & 1 \\
Portugal & 1 \\
Romania & 1 \\
Singapore & 1 \\
Slovakia & 1 \\
Taiwan & 1 \\
Ukraine & 1 \\
United & Arab \\
Emirates & 1 \\
Undefined & 212 \\
\hline
\end{tabular}

\section{Language}

It is also found that most of the paper published related to the ingenuity research that indexed in Scopus are in English language (432) represented $92.9 \%$ of the total publications. One of the papers has been published in three (3) different languages which is English, French and Spanish. Eleven (11) of the papers have been published in dual languages which three (3) of them have been prepared in English and French and two (2) each for English and German, English and Italian, English and Portuguese, and English and Spanish. The summary of this finding is shown in Table 5.

Table.5 Language

\begin{tabular}{lll}
\hline Language & Total & Percent $(\%)$ \\
\hline English & 432 & 92.90 \\
Spanish & 9 & 1.94 \\
French & 8 & 1.72 \\
German & 4 & 0.86 \\
Japanese & 4 & 0.86 \\
\hline
\end{tabular}

\begin{tabular}{lll} 
Portuguese & 4 & 0.86 \\
Italian & 3 & 0.65 \\
Dutch & 1 & 0.22 \\
Undefined & 13 & 2.80 \\
\hline
\end{tabular}

\section{Subject Area}

This study also tabled the subject area covered under the ingenuity research. It was found out that most of the ingenuity research are from the area of engineering, medicine, arts and humanities and social sciences. Table 6 below summarizes the distribution on research based on their subject area.

Table.6 Subject Area

\begin{tabular}{|c|c|c|c|}
\hline Subject Area & $\begin{array}{l}\text { To } \\
\text { tal }\end{array}$ & Subject Area & $\begin{array}{l}\text { To } \\
\text { tal }\end{array}$ \\
\hline & 10 & Physics & \\
\hline Engineering & 2 & $\begin{array}{l}\text { Astronomy } \\
\text { Chemical }\end{array}$ & 18 \\
\hline Medicine & 92 & Engineering & 15 \\
\hline Arts and Humanities & 80 & Nursing & 14 \\
\hline Social Sciences & 73 & Chemistry & 12 \\
\hline $\begin{array}{l}\text { Business, Management } \\
\text { and Accounting }\end{array}$ & 56 & Undefined & 11 \\
\hline $\begin{array}{l}\text { Biochemistry, Genetics } \\
\text { and Molecular Biology }\end{array}$ & 29 & Energy & 10 \\
\hline Materials Science & 29 & Mathematics & 8 \\
\hline $\begin{array}{l}\text { Computer Science } \\
\text { Economics, Econometrics }\end{array}$ & 25 & $\begin{array}{l}\text { Psychology } \\
\text { Health }\end{array}$ & 8 \\
\hline $\begin{array}{l}\text { and Finance } \\
\text { Pharmacology, }\end{array}$ & 24 & Professions & 6 \\
\hline Toxicology & & Decision & \\
\hline Pharmaceutics & 21 & Sciences & 3 \\
\hline $\begin{array}{l}\text { Multidisciplinary } \\
\text { Agricultural and }\end{array}$ & 19 & Neuroscience & 3 \\
\hline Biological Sciences & 18 & Veterinary & 3 \\
\hline $\begin{array}{l}\text { Earth and Planetary } \\
\text { Sciences }\end{array}$ & 18 & $\begin{array}{l}\text { Dentistry } \\
\text { Immunology and }\end{array}$ & 1 \\
\hline Environmental Science & 18 & Microbiology & 1 \\
\hline
\end{tabular}

\section{Keywords}

This study also analyzes the keywords that have been used to categorized some of the specific areas covered under ingenuity study. The summary of this finding is shown in Table 7

Published By: 
Table 7. Top 18 Keywords

\begin{tabular}{|c|c|c|c|}
\hline Keyword & $\begin{array}{l}\text { Tot } \\
\text { al }\end{array}$ & Keyword & $\begin{array}{l}\text { Tot } \\
\text { al }\end{array}$ \\
\hline Human & 73 & Nonhuman & 13 \\
\hline Article & 71 & $\begin{array}{l}\text { Controlled Study } \\
\text { Organization and }\end{array}$ & 12 \\
\hline Humans & 46 & Management & 12 \\
\hline United States & 25 & Design & 11 \\
\hline Priority Journal & 22 & Editorial & 11 \\
\hline Male & 16 & Aged & 10 \\
\hline Methodology & 16 & Animal & 10 \\
\hline Animals & 14 & Education & 10 \\
\hline Note & 14 & Students & 10 \\
\hline
\end{tabular}

\section{Text Analysis of the Article Titles}

This research uses WordSift (wordsift.org), a program that helps to rapidly define significant phrases that appear in the text, to generate the word cloud for the article name. With a maximum of 100 phrases and a n-scale environment, word cloud results can be viewed as shown in Figure 1. Apart from the term "ingenuity" that we used as the keyword in the search engine and excluded from the assessment, it can be seen from the word cloud that other words, including organization, innovation, creativity, humanity, and design, were also outstanding. The frequency of top phrases based on the paper title was summarized in Table 8.

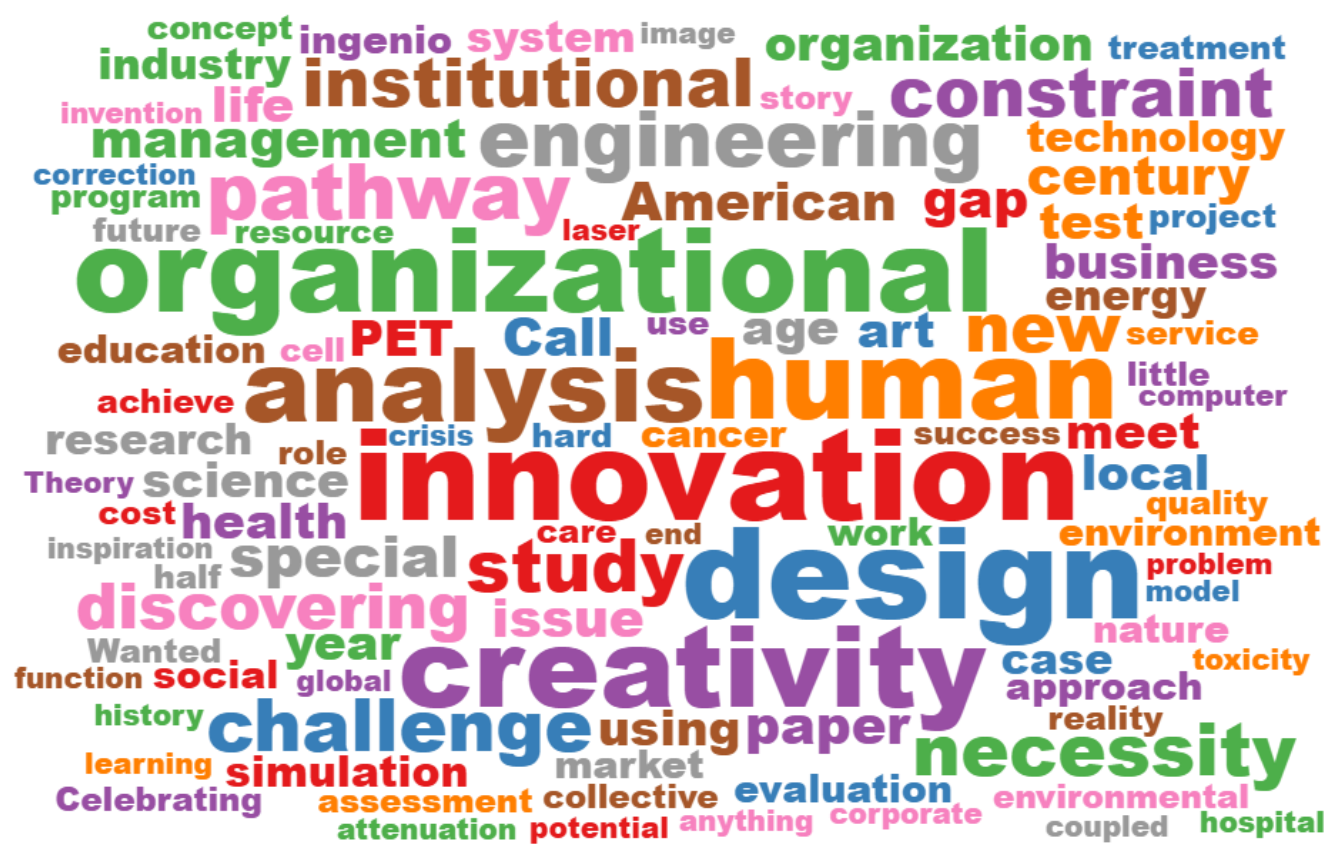

Fig. 1 Word Cloud from the Source Title of the Articles

Table. 8 Frequency And Top Words

\begin{tabular}{cccc}
\hline Word & Occurrences & Frequency & Rank \\
\hline organizational & 22 & $0.70 \%$ & 1 \\
innovation & 21 & $0.70 \%$ & 1 \\
creativity & 21 & $0.70 \%$ & 1 \\
human & 21 & $0.70 \%$ & 1 \\
design & 20 & $0.70 \%$ & 1 \\
analysis & 18 & $0.60 \%$ & 2 \\
engineering & 14 & $0.50 \%$ & 3 \\
necessity & 13 & $0.40 \%$ & 4 \\
institutional & 12 & $0.40 \%$ & 4 \\
\hline constraints & 12 & $0.40 \%$ & 4 \\
\end{tabular}

\section{CONCLUSION AND DISCUSSION}

This paper describes a bibliometric analysis to gain a vivid insight into the ingenuity literature's historical review, trends and contributions. Scopus database is used in the title of the paper to collect all the research that has the word "ingenuity." This study shows that research on this subject began as early as 1854 and grew with the greatest publishing in 2014 in 2001. According to the geographic distribution of the literature, the United States has the biggest amount of publications compared to other progressive nations such as the United Kingdom and Canada, and thus the bulk is released in English.Our results infer that the execution of the concept of ingenuity embedded in the subject of the papers has been disseminated to a large extent across multidisciplines whereby the word "human" is another term used as a keyword to explore ingenuity.

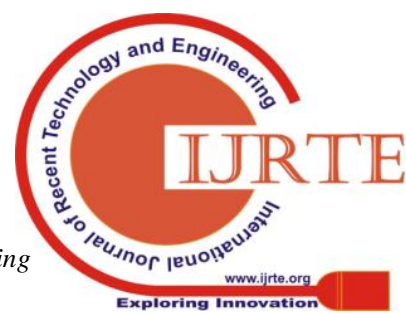


The ' word ' or ' term ' sampled on the subject of the papers was limited and solely on ingenuity, although this study succeeded in revealing the status and scope of research articles using ingenuity as their title. The term or word used is not regarded as the same or synonymous term as innovation, creativity and cutting edge. Findings from this study provided researchers with an opportunity to address the limitations and identify research gaps in this area for future research. Further research may also be conducted to scrutinize paper content entitled Ingenuity through profile as well as study extension domain. This can be done to circumscribe and categorize paper content according to other criteria such as quotation, theory tested, variable investigated, methodology, methodology used and its main contribution.

In the research, there were several constraints intrinsic in the database used and the authors ' search query. Despite the reality that Scopus is one of the biggest databases, it should be stressed that there are still unindexed journals or journals indexed by other databases, which could have rejected publications for such journals. Moreover, based on the title of associated papers, this research also concentrated only on subjects related to ingenuity. Other literatures related to ingenuity were excluded but did not have a appropriate specific document title. Whatever the constraints, this research is among the pioneers in exploring the information of the published literature on ingenuity on bibliometric indices.

\section{ACKNOWLEDGMENTS}

We would like to thank all the reviewers in enhancing this paper for their positive remarks and suggestions.

\section{REFERENCES}

1. D. McGregor, The Human Side of Enterprise. (McGraw-Hill, 1960).

2. T. Homer-Dixon, "The Ingenuity Gap: Can Poor Countries Adapt to Resource Scarcity?," Popul. Dev. Rev., 21(3), 587, (1995).

3. T. F. Homer-Dixon, The Ingenuity Gap: How Can We Solve The Problems of the Future?(Knopf, 2000).

4. T. F. Homer-Dixon, The Ingenuity Gap: Facing the Economic, Environmental, and other Challenges of an Increasingly Complex and Unpredictable World. (Vintage Books, 2002).

5. R. (Priya) Kannan-Narasimhan, "Organizational Ingenuity in Nascent Innovations: Gaining Resources and Legitimacy through Unconventional Actions," Organ. Stud., 35(4), 483-509, (2014).

6. S. A. M. Dolmans, E. van Burg, I. M. M. J. Reymen, and A. G. L. Romme, "Dynamics of Resource Slack and Constraints: Resource Positions in Action,” Organ. Stud., 35(4), 511-549, (2014).

7. B. D. Rosso, "Creativity and Constraints: Exploring the Role of Constraints in the Creative Processes of Research and Development Teams," Organ. Stud., 35(4), 551-585, (2014).

8. S. Lombardo and R. Kvålshaugen, "Constraint-Shattering Practices and Creative Action in Organizations," Organ. Stud., 35(4), 587-611, (2014).

9. K. Walker, F. Schlosser, and D. Deephouse, "Organizational ingenuity and the paradox of embedded agency: The case of the embryonic Ontario solar energy industry," Organ. Stud., (2014).

10. J. M. Korhonen and L. Välikangas, "Constraints and Ingenuity: The Case of Outokumpu and the Development of Flash Smelting in the Copper Industry," in Handbook of Organizational and Entrepreneurial Ingenuity, B. Honig, J. Lampel, and I. Driori, Eds. (2014).

11. N. Senf, J. Koch, and W. Rothmann, "Ingenuity as creative unfolding: Framing the frame in haute cuisine," in Handbook of Organizational and Entrepreneurial Ingenuity, B. Honig, J. Lampel, and I. Driori, Eds. (2014).

12. A.C. O. Siqueira, S. R. H. Mariano, J. Moraes, and G. Gorse, "Creating Innovative Solutions in Microfinance and the Role of Organizational
Ingenuity," in Handbook of Organizational and Entrepreneurial Ingenuity, B. Honig, J. Lampel, and I. Driori, Eds. (2014).

13. J. Lampel, B. Honig, and I. Drori, "Organizational Ingenuity: Concept, Processes and Strategies," Organ. Stud., 35(4), 465-482, (2014).

14. M. Ungerer, M. Pretorius, and J. Herholdt, Viable Business Strategies: a Field book for Leaders. (Randburg: Knowres Publishing, 2011).

15. J. Keiser and J. Utzinger, "Trends in the core literature on tropical medicine: a bibliometric analysis from 1952-2002," Scientometrics, 62(3), 351-365, (2005).

16. R. Tang and M. Thelwall, "U.S. academic departmental Web-site interlinking in the United States Disciplinary differences," Libr. Inf. Sci. Res., 25(4), 437-458, (2003).

17. H. Schutz and B. Six, "More than 7000 Pages of Social-Psychology-A Journal in Retrospect," Zeitschrift fur Sozialpsychologie, 25(1), 5-17, (1994).

18. T. Braun, W. Glänzel, and H. Grupp, "The scientometric weight of 50 nations in 27 science areas, 1989-1993. Part I. All fields combined, mathematics, engineering, chemistry and physics," Scientometrics, 33(3), 263-293, (1995)

19. A..E. Bayer and J. Folger, "Some Correlates of a Citation Measure of Productivity in Science," Sociol. Educ., 39(4), 381, (1966).

20. E. Garfield, "Keywords plus-ISIS breakthrough retrieval method. Expanding your searching power on current-contents on diskette," Curr. Contents, 32, 5-9, (1990).

21. J. Chen, "Perspective Innovation Research of Global," in Academy of Management Annual Meeting, (2010). 